\title{
Clinical course of coronavirus disease 2019 in 11 patients after thoracic surgery and challenges in diagnosis
}

\author{
Shu Peng, MD, PhD, ${ }^{\mathrm{a}}$ Liu Huang, MD, ${ }^{\mathrm{b}}$ Bo Zhao, MD, ${ }^{\mathrm{a}}$ Shuchang Zhou, MD,
} Irene Braithwaite, $\mathrm{MD}, \mathrm{PhD},{ }^{\mathrm{d}} \mathrm{Ni}$ Zhang, $\mathrm{MD},{ }^{\mathrm{a}}$ and Xiangning $\mathrm{Fu}, \mathrm{MD}^{\mathrm{a}}$

\section{ABSTRACT}

Objectives: To illustrate the clinical course and difficulties in early diagnosis of coronavirus disease 2019 (COVID-19) in patients after thoracic surgery.

Methods: We retrospectively analyzed the clinical course of the first 11 patients diagnosed with COVID-19 after thoracic surgery in early January 2020. Postoperative clinical, laboratory, and radiologic records and the time line of clinical course were summarized. Potential prognostic factors were evaluated.

Results: In the 11 confirmed cases ( 3 female, 8 male), median days from symptom onset to case detection was 8 . Insidious symptom onset and misinterpreted postoperative changes on chest computed tomography (CT) resulted in delay in diagnosis. There were 3 fatalities due to respiratory failure, whereas 4 severe and 4 mild cases recovered and were discharged. All patients had once experienced leukocytosis and eosinopenia. Remittent fever and resected lung segments $\geq 5$ were associated with fatality.

Conclusions: The case fatality rate of postsurgical patients subsequently diagnosed with COVID-19 was $27.3 \%$. Insidious symptom onset, postoperative leukocytosis with lymphopenia, and postsurgical CT changes overshadowed the early signs of viral pneumonia. Dynamic symptom monitoring, serial chest CTs, and tests for viral RNA and serum antibody improve the chance for prompt detection of COVID-19. Consideration should be given to preadmission and preoperative screening and strict contact isolation during the postoperative period. (J Thorac Cardiovasc Surg 2020;160:585-92)

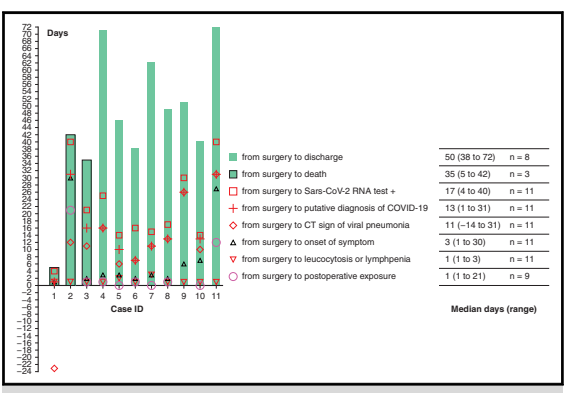

Timeline of events in coronavirus disease 2019 for 11 patients after thoracic surgery.

\section{CENTRAL MESSAGE}

The early signs of COVID-19 were disguised in 11 postoperative thoracic patients, resulting in a $27.3 \%$ fatality rate.

\section{PERSPECTIVE}

Pre- and postsurgical presentation of thoracic malignancy may appear similar to early signs of COVID-19. During the pandemic, a high suspicion for COVID-19 infection should be retained, preoperative screening for COVID-19, postoperative isolation, and dynamic postoperative clinical, radiological, and laboratory testing instead of at a single time point is recommended.

See Commentaries on pages 593, 594, and 595

The pandemic of coronavirus disease 2019 (COVID-19) caused the cancelation of elective surgeries and clinics in many regions in China. However, emergency surgeries

\footnotetext{
From the Departments of ${ }^{\mathrm{a}}$ Thoracic Surgery, ${ }^{\mathrm{b}}$ Oncology, and ${ }^{\mathrm{c}}$ Radiology, Tongji Hospital, Tongji Medical College, Huazhong University of Science and Technology, Wuhan, China; and ${ }^{\mathrm{d}}$ Medical Research Institute of New Zealand, Wellington, New Zealand.

This work was supported by the National Key Research and Development Plan, Key Research Projects of Precision Medicine, grant number: 2017YFC0907900.

Drs Peng and Huang contributed equally to this article. Drs Fu and Zhang are co-corresponding authors.

Received for publication March 23, 2020; revisions received April 2, 2020; accepted for publication April 4, 2020; available ahead of print April 10, 2020.

Address for reprints: Xiangning Fu, MD, Department of Thoracic Surgery, Tongji Hospital, Tongji Medical College, Huazhong University of Science and Technology, 1095 Jie Fang Ave, Wuhan 430030, P.R. China (E-mail: fuxn2006@aliyun. com).

$0022-5223 / \$ 36.00$

Copyright (c) 2020 by The American Association for Thoracic Surgery

https://doi.org/10.1016/j.jtcvs.2020.04.005
}

continue to be performed, and urgent surgeries in cancer treatment cannot be postponed indefinitely. Since severe acute respiratory syndrome coronavirus 2 (Sars-CoV-2) is infectious in asymptomatic carriers with a variable incubation period (0-24 days), ${ }^{1}$ the recognition of infection in clinics and wards is important for physicians of all specialties. Although $80 \%$ of patients present with apparently mild respiratory infection, COVID-19 has a case fatality rate of approximately $2 \% .^{2-4}$ Thoracic malignancy may also present with mild respiratory symptoms. In addition, after thoracic surgery patients may also have cough,

(U) Scanning this QR code will take
you to the article title page to
access supplementary informa-
tion.




\section{Abbreviations and Acronyms}

COVID-19 = coronavirus disease 2019

$\mathrm{CT} \quad=$ computed tomography

GGO = ground-glass opacity

rt-PCR = real-time reverse transcriptasepolymerase chain reaction

Sars-Cov- $2=$ severe acute respiratory syndrome coronavirus 2

dyspnea, reactive fever, and postoperative radiologic changes. These postoperative changes may overshadow the symptoms of COVID-19. Without sufficient experience and precaution, prompt diagnosis of COVID-19 may be delayed and nosocomial transmission may occur.

This study describes the clinical course of 11 patients who underwent thoracic surgery for malignancy in the early phase of the pandemic before the formal declaration of outbreak and were consequently diagnosed with COVID19. We illustrate the risk of thoracic surgery during this pandemic.

\section{METHODS}

\section{Study Population}

To be considered as a possible case, a patient needed to have been admitted for and undergone thoracic surgery at the Department of Thoracic Surgery at the central campus of Tongji Hospital, Tongji Medical College, Huazhong University of Science and Technology between January 1 and January 24, 2020. All postsurgical patients who tested positive for COVID-19 by real-time reverse transcriptase-polymerase chain reaction (rt-PCR) were eligible for inclusion in the case series.

\section{Classification of COVID-19}

Cases were classified as nonsevere, severe, or critical according to the clinical guideline of the China National Health Commission. ${ }^{5}$ Patients were defined as "critical" if they ever met any of the following criteria: respiratory failure requiring mechanical ventilation, septic shock, or multiple organ dysfunction in the intensive care unit. Patients were defined as "severe" when suffering from either dyspnea with respiratory rate $\geq 30 / \mathrm{min}$ ute, or partial pressure of arterial oxygen/percentage of inspired oxygen ratio $<300 \mathrm{~mm} \mathrm{Hg}$ or blood oxygen saturation $\leq 93 \%$, or lung infiltrates $>50 \%$ within 24 to 48 hours. The remaining cases were defined as "nonsevere." Regardless of consequent recovery, cases were classified by the most severe criteria they ever met during the postsurgical course.

\section{Exposure History}

Positive exposure history was defined as a history of close contact with family members suspicious for COVID-19 infection, or if a patient sharing their ward had confirmed COVID-19. Fever was defined as an axillary temperature more than $37.3^{\circ} \mathrm{C}$.

\section{Definitions}

A putative case was defined as clinical suspicion of COVID-19 resulting isolation of patient before rt-PCR detection of viral RNA. Delay in diagnosis means COVID-19 was not initially suspected due to insidious onset of symptoms that mimicked the usual postoperative course, or due to the first computed tomography (CT) scan of the chest after surgery being interpreted as postoperative changes rather than as being suspicious for viral pneumonia. The case ID number (1-11) represents a specific patient and is used to identify that same patient consistently in all figures, tables, and text.

\section{Data Collection and Evaluation}

Demographics, comorbidities, and clinical documents were collected from the Hospital Information System. For accuracy, 2 researchers independently recorded data using a standardized data-collection form. First symptom and onset of disease was derived from medical records, temperature charts, patient recall, and recall of their primary care surgeons. Possible time of exposure was determined through contact tracing, which included evaluation of patient recall, duration of patient placement within beds and wards, co-location with other patients ultimately diagnosed with COVID-19, and information about families and visitors during their hospitalization. CT images of the chest were analyzed and recorded by 1 radiologist and 1 thoracic surgeon independently. Researchers were not involved in collection of biological samples for rt-PCR, and setting of CT parameters in this retrospective analysis, protocol for $\mathrm{rt}_{-} \mathrm{PCR}^{6}$ and chest $\mathrm{CT}^{7}$ were same to as that in the reference article from Tongji hospital.

\section{Management of Patients}

All patients had perioperative education, including breathing exercises and "intention to cough after operation" once every 2 hours during the day to improve lung expansion. As we experienced rapidly changing patient outcomes in the midst of a pandemic, our treatment modalities also changed rapidly, including an initial period in which patients received prophylactic antibiotic and ambroxol after the case ID 1 being diagnosed as COVID-19, a practice that was later stopped. As our experience with and our understanding of COVID-19 increased, we standardized our approach to initiate oral oseltamivir and moxifloxacin and a CT of the chest immediately after the first onset of fever. Rt-PCR tests were requested if a CT of the chest showed characteristics consistent with viral pneumonia. Rectal diclofenac ( $25 \mathrm{mg}$, every 6 hours) was used to control pain and fever. Patients were transferred to isolation wards as soon as COVID-19 was suspected. All patients received supportive care with oxygen supplementation regardless of their oxygen saturations. Information regarding nonspecific antivirals, corticosteroid and mechanical ventilation are shown in Table E1.

\section{Statistics and Ethics}

Ethical application was made to and approved by the institutional review board of Tongji Hospital, Tongji Medical College, Huazhong University of Science and Technology (TJ-IRB20200307; date of approval: March $3,2020)$. Consent from the COVID-19 cases analyzed in this report was waived due to its retrospective nature and that data would be deidentified at publication. Median and range or mean \pm standard deviation was used to describe continuous data. Single comparisons were performed by independent samples $t$ test. Normality was tested by the Shapiro-Wilk test. Categorical variables were assessed by Fisher exact test to evaluate associations between case fatality and surgical, laboratory, and clinical features. All analysis was computed by IBM SPSS Statistics (version 24; IBM Corp, Armonk, NY).

\section{RESULTS}

\section{Baseline Characteristics and Epidemiology}

In total, 205 patients were admitted to the surgical unit between January 1 and January 24, 2020. On January 24, all nonemergent surgeries were cancelled as the pandemic nature of COVID-19 was realized. Therefore, 84 patients were consequently discharged home without surgical intervention. Of the 121 patients who had already been operated 
on, 13 developed postoperative fever and were considered putative cases of COVID-19, of whom 11 had COVID-19 confirmed by rt-PCR and were included in this case series. There was 1 patient who developed fever and died at home without autopsy who was not included in this case series due to uncertainty of cause of death. Unknown to the admitting staff, and before the pandemic nature of COVID-19 being recognized, 10 patients had postoperative positive exposure history to COVID-19 (Figure 1). Evidence of nosocomial transmission is apparent in the majority. The date of first exposure in case ID 9 is uncertain, since her husband had COVID-19 diagnosed before her onset of symptoms.

Demographics, comorbidities, and pathology of neoplasm are shown in Table 1. In general, no one had impaired liver and renal function preoperatively, and 9 patients had thoracic malignancies. All had undergone radical tumor resection within 1 month of developing symptoms consistent with COVID-19 infection. Duration from possible postoperative exposure to onset of symptom ranges from 1 to 15 days (Figure 1).

\section{Onset of Symptom and Diagnosis}

Events from surgery to diagnosis of COVID-19 are shown in Figure 1. Median days from surgery to putative COVID-19 infection was 13 (range 1-31 days), to positive rt-PCR test was 17 (range 4-40 days), to death was 35 (range $5-42$ days, $\mathrm{n}=3$ ), and to discharge upon recovery was 50 days (38-72 days, $\mathrm{n}=8$ ). Of the 11 confirmed cases, symptom onset included dry cough (1/11), dyspnea (2/ $11)$, and fever (8/11). There were 3 cases in which infection was not detected at their insidious onset of symptoms but only after fever developed and CT of the chest was done. Case ID 9 had dry chough after resuscitation with tracheal intubation on the day of operation due to hypokalemia with sudden cardiac arrest. She was discharged home 12 days postoperatively, and her infection was detected after another 12 days by chest CT after her husband had confirmed COVID-19 infection. Case ID 7 had a history of bronchial asthma and became dyspneic 4 days after right upper lobectomy. A CT was taken 7 days later after onset of fever at which time COVID-19 was putative.

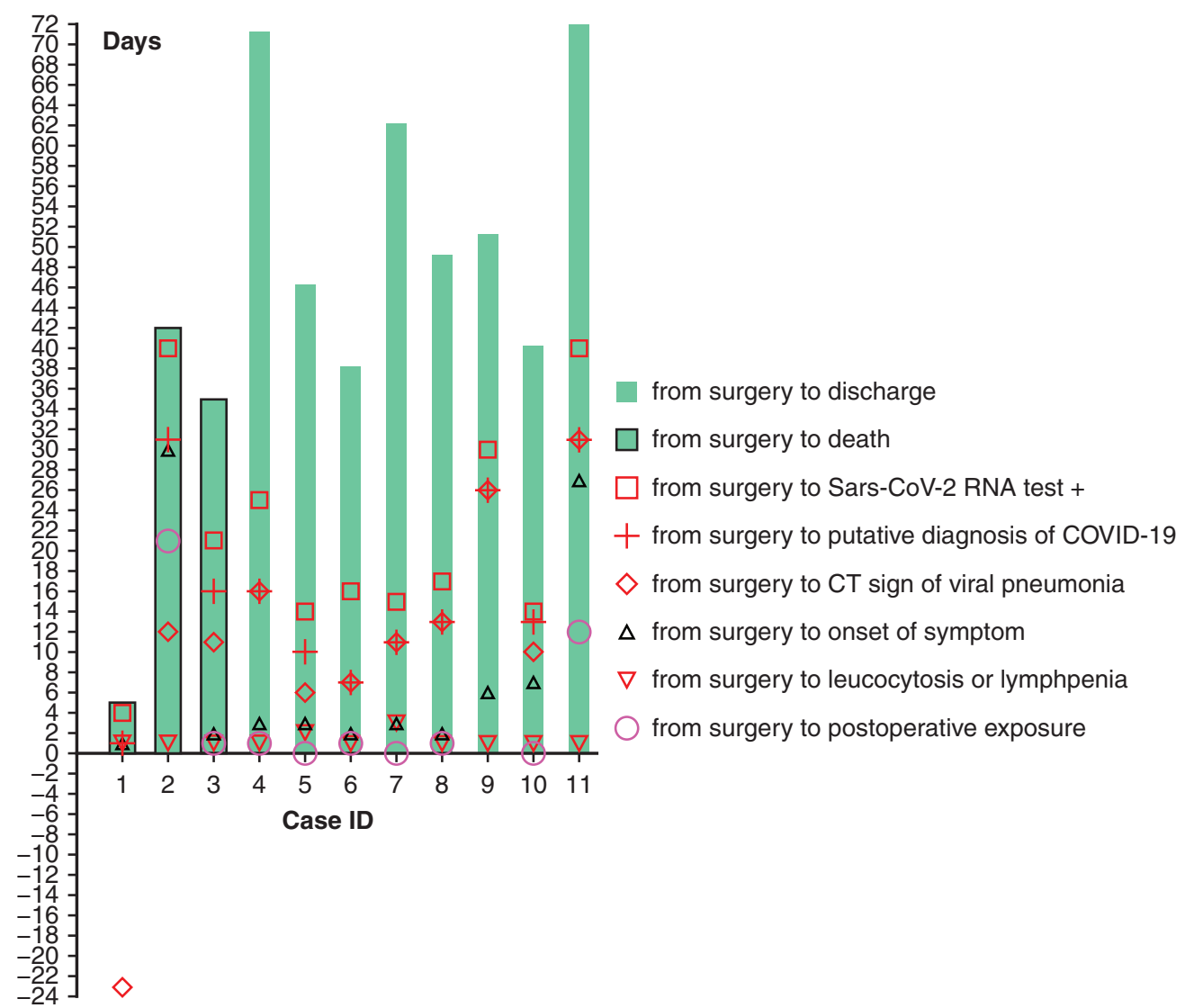

\begin{tabular}{ll}
\hline 50 (38 to 72$)$ & $\mathrm{n}=8$ \\
\hline $35(5$ to 42$)$ & $\mathrm{n}=3$ \\
\hline $17(4$ to 40$)$ & $\mathrm{n}=11$ \\
\hline $13(1$ to 31$)$ & $\mathrm{n}=11$ \\
\hline $11(-14$ to 31$)$ & $\mathrm{n}=11$ \\
\hline $3(1$ to 30$)$ & $\mathrm{n}=11$ \\
\hline $1(1$ to 3$)$ & $\mathrm{n}=11$ \\
\hline $1(1$ to 21$)$ & $\mathrm{n}=9$ \\
\hline
\end{tabular}

Median days (range)

FIGURE 1. Timeline of events in the clinical course of coronavirus disease 2019 in 11 patients after thoracic surgery. IDs 1 , 2, and 3 represent 3 critical patients dead from respiratory failure. Severe cases (IDs 4, 5, 6, 7) and nonsevere cases (IDs 8, 9, 10,11) were discharged upon recovery. Median of days from surgery to death was 35 (range $5-42, \mathrm{n}=3$ ), and from surgery to discharge upon recovery was 50 (range $38-72, \mathrm{n}=8$ ). (Date of first exposure for case ID 1 and case ID 9 were uncertain.) Sars-Cov-2, Severe acute respiratory syndrome coronavirus 2; COVID-19, coronavirus disease 2019; CT, computed tomography. 
TABLE 1. Baseline characteristics of 11 patients before COVID-19 infection

\begin{tabular}{|c|c|}
\hline Baseline characteristics & n $(\%)$ \\
\hline Age, y & \\
\hline $\begin{array}{l}\text { Median (range) } \\
50-59 \\
60-69\end{array}$ & $\begin{array}{l}61(51-69) \\
5(45.5) \\
6(54.5)\end{array}$ \\
\hline $\begin{array}{l}\text { Sex } \\
\quad \text { Male } \\
\text { Female }\end{array}$ & $\begin{array}{l}8(72.7) \\
3(27.3)\end{array}$ \\
\hline $\begin{array}{l}\text { Chief complains before operation } \\
\text { CT detected neoplasm (asymptomatic) } \\
\text { Cough } \pm \text { sputum } \\
\text { Chest tightness } \\
\text { Dysphagia }\end{array}$ & $\begin{array}{l}5(45.5) \\
4(36.4) \\
1(9.1) \\
1(9.1)\end{array}$ \\
\hline $\begin{array}{l}\text { Comorbidities } \\
\text { Hypertension } \\
\text { CAD } \\
\text { Diabetes } \\
\text { COPD } \\
\text { History of colon cancer } \\
\text { Cigarette smoking }\end{array}$ & $\begin{array}{l}2(18.2) \\
3(27.3) \\
0(0.0) \\
3(27.3) \\
1(9.1) \\
6(54.5)\end{array}$ \\
\hline $\begin{array}{l}\text { Preoperative pathology } \\
\text { Lung adenocarcinoma } \\
\text { Esophageal squamous cell carcinoma } \\
\text { Not available }\end{array}$ & $\begin{array}{l}2(18.2) \\
2(18.2) \\
9(63.6)\end{array}$ \\
\hline GGO on preoperative $\mathrm{CT}$ images & $2(18.2)$ \\
\hline $\begin{array}{l}\text { Postoperative complications } \\
\text { Prolonged air leak } \\
\text { Sudden cardiac rest from hypokalemia }\end{array}$ & $\begin{array}{l}1(9.1) \\
1(9.1) \\
1(9.1)\end{array}$ \\
\hline $\begin{array}{l}\text { Pathology of resected neoplasm } \\
\text { Lung cancer } \\
\text { Esophageal cancer } \\
\text { Pulmonary sclerosing pneumocytoma } \\
\text { Bronchiectasis }\end{array}$ & $\begin{array}{l}7(63.6) \\
2(18.2) \\
1(9.1) \\
1(9.1)\end{array}$ \\
\hline $\begin{array}{l}\text { TNM stages for lung cancer patients } \\
\text { IA } \\
\text { IB } \\
\text { IIIA }\end{array}$ & $\begin{aligned} 4 * & (27.3) \\
1 * & (9.1) \\
3 & (27.3)\end{aligned}$ \\
\hline $\begin{array}{l}\text { TNM stages for esophagus cancer patients } \\
\text { IB } \\
\text { IIB }\end{array}$ & $\begin{array}{l}1(9.1) \\
1(9.1)\end{array}$ \\
\hline
\end{tabular}

$C T$, Computed tomography; $C A D$, atherosclerosis of coronary artery; $C O P D$, chronic obstructive pulmonary disease; $G G O$, ground-glass opacity; TNM, tumor-nodemetastasis. ${ }^{*}$ Case ID 10 has synchronous multiple primary lung adenocarcinoma (stage IA and stage IB respectively). Detailed information for each patient is listed in supplementary table.

\section{CT Features of COVID-19 After Thoracic Surgery}

All patients had CT of the chest before and after surgery. Of the 11 cases, Case ID 1 and ID 11 had preoperative ground-glass opacifications (GGOs). Case 11 had multiple GGOs proven as synchronous multiple primary lung adenocarcinoma on pathology (stage IA and stage IB, Tables 1 and E2). Case ID 1 (Figure 2) was asymptomatic during the 3 weeks prior to operation with a normal leucocyte and lymphocyte count; he had abrupt fever within 12 hours after operation, followed by rapid deterioration and death within 5 days. On retrospective analyzes of his chest CT 23 days prior to operation, we revealed subpleural illdefined GGO in the right lower lobe with increased extent and intensity 9 day later (Figure 2).

Of the 10 cases deemed to have had postoperative exposure (except for case ID 1), 6 (case IDs 4, 6, 7, 8, 9, 11) were diagnosed putatively after the first postoperative chest CTs in which the following features were noted: peripheral or subpleural distribution, multifocal located ill-defined GGO, sign of "crazy-paving," bronchial wall thickening, and irregular consolidations that were rapidly increasing in extent and intensity (Figure 2).

The first postoperative CTs of the chest of another 4 patients (ID 2, 3, 5, 10) were initially interpreted as having postoperative changes but were later realized to be indicative of COVID-19. These CT scans contained the following features: cord-like consolidation or opacity, irregular patchy consolidation, irregular GGO with diameter less than $10 \mathrm{~mm}$, subpleural consolidations, and reticular changes (Figure 3 ).

\section{Clinical Characteristics and Outcomes}

At the last follow-up on March 27 2020, 3 critical cases had died (Figure 1, IDs 1, 2, 3), and 4 severe (IDs 4, 5, 6, 7) and 4 mild cases (IDs 8, 9, 10, 11) were discharged upon recovery.

Clinical and laboratory features are shown in Table 2, and detailed information of each patient is listed in Table E1. The median of symptom-onset days after operation was 3 (range 1-30 days). In general, all patients had fever and dyspnea. The 3 critical cases had remittent fever until death.

All patents had normal complete blood count and clinical biochemistry preoperatively, with leukocytosis or lymphopenia at day 1 or day 3 postoperatively followed by eosinopenia. The 3 critical cases had an absolute eosinophil count approximating $0\left(\times 10^{9} / \mathrm{L}\right)$ when arterial oxygen saturation dropped below $93 \%$. In summary, leukopenia occurred in 2 cases $(18.2 \%), 8$ patients had elevated liver enzymes $(72.7 \%)$, and all patients had hypoproteinemia, hypoalbuminemia, and elevated lactate dehydrogenase.

\section{Potential Risk Factors}

Factors potentially associated with fatal cases $(\mathrm{n}=3)$ are shown in Table 3. None of the preoperative factors was associated with death. However, resected lung volume ( $\geq 5$ segments), persistent fever, and postoperative reduction of total protein and albumin were significantly associated with fatality $(P<.05)$. Increase in lactate dehydrogenase and liver enzymes also showed marginal association with death $(P=.05, P=.055$, respectively). 


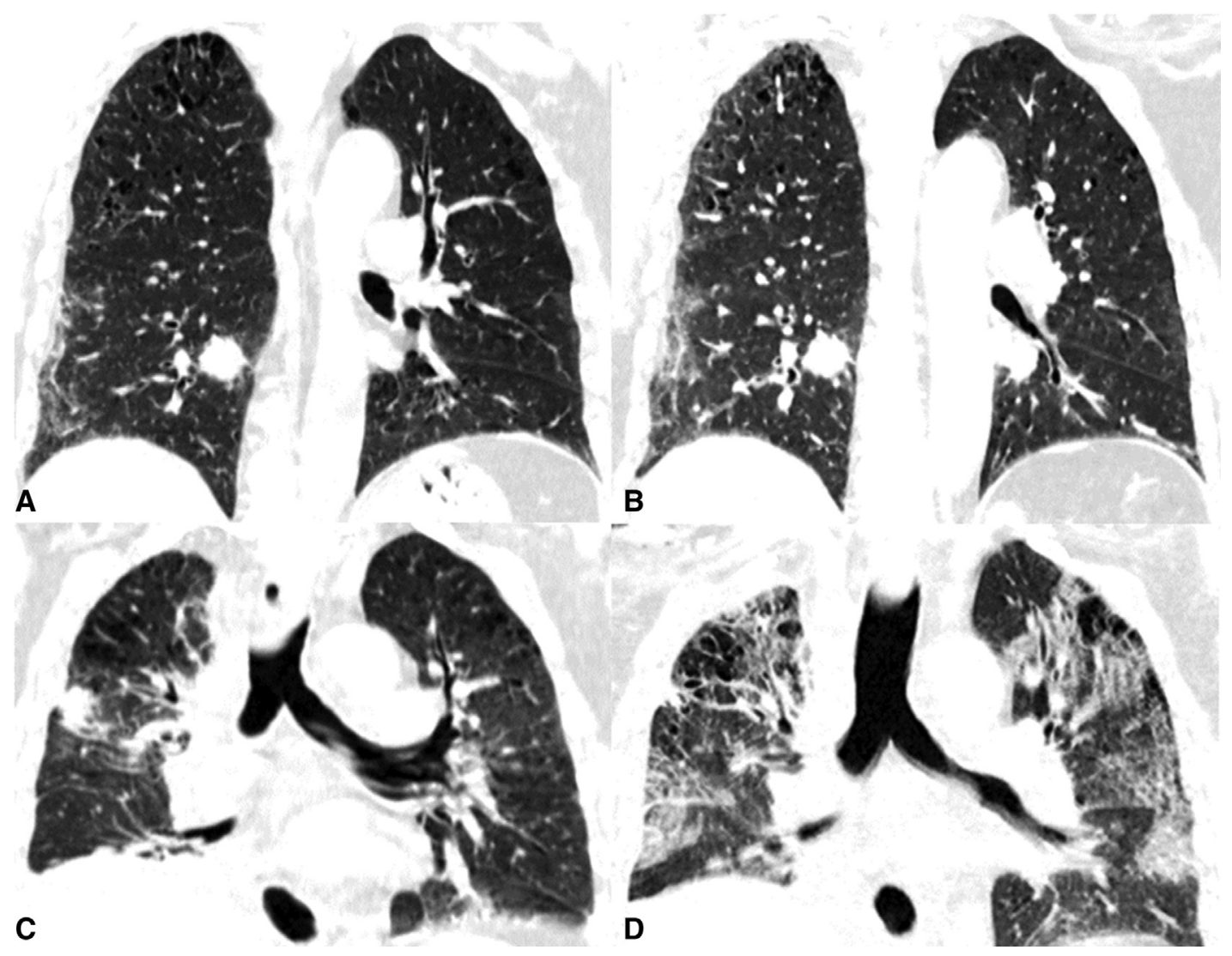

FIGURE 2. CT of the chest of a 63-year-old male patient (case ID 1) with progression of COVID-19 before and after operation. Biopsy of solid tumor in the right lower lobe indicated adenocarcinoma. The subpleural ill-defined ground-glass opacification had increased extent and intensity from 23 days (A) to 14 (B) days preoperatively. He was asymptomatic and had abrupt onset of fever $\left(39^{\circ} \mathrm{C}\right)$ within 12 hours after right lower lobectomy. C, Postoperative $\mathrm{CT}$ at day 2 shows postoperative changes and sign of consolidation. D, On day 4, he had extended bilateral reticular consolidation and sign of bronchogram. He died from respiratory failure 5 days after surgery.

\section{DISCUSSION}

Across the COVID-19 cohort in China, the proportion of severe and critical disease was $2 \%$ to $6.1 \%$, and $13.8 \%$, respectively, ${ }^{2-4}$ and was $27.3 \%$ and $36.4 \%$, respectively, after thoracic surgery in this case series. It appears that Sars-CoV-2 may significantly increase the risk of death during the thoracic postoperative period. In addition, the virus is contagious during the incubation period, which may lead to nosocomial transmission even within well-organized hospitals with strict infection control procedures.

The overlap between symptoms of COVID-19 and the usual thoracic postoperative clinical course may result in delayed diagnosis: fever and cough from reactive pleural effusion and atelectasis are common after thoracic surgery ${ }^{8}$; dyspnea may be secondary to lung resection and chronic obstructive lung disease; many thoracic postoperative patients suffer chest tightness and fatigue, loss of appetite, and nausea due to postoperative analgesics; and antibiotics are usually self-limiting. Therefore, in this pandemic, thoracic surgeons must make their patient rounds with greater caution to distinguish infection from noninfectious symptoms, perhaps to assume infection by default. As a result of our experiences, we have provided hospitalized patients with a daily self-checking form to record possible symptoms with onset, duration, severity, and dynamic changes to help early detection of infection.

Case fatality in this study was significantly associated with resected lung segments $(\geq 5)$, severity of postoperative hypoproteinemia or hypoalbuminemia, and peak value of lactate dehydrogenase. We cannot determine causality, nor control for other factors, including comorbidities and surgery. Case ID 1 with a smoking index of 1600 had an asymptomatic period for 3 weeks and had onset of fever within 12 hours after operation. Whether this was due to a long period of incubation (known to be up to 24 days) or exacerbated by the stress of the surgical procedure cannot be assessed. Case ID 2 had history of colon cancer, marginal pulmonary function test (forced expiratory volume in $1 \mathrm{sec}-$ ond $1.39 \mathrm{~L} / \mathrm{s}$, forced expiratory volume in 1 second/forced vital capacity $70.1 \%$ ), and a smoking index of 1600 . Case ID 3 had arterial hypertension (stage I, high risk), left ventricular dilatation (ejection fraction: 63\%), and coronary 


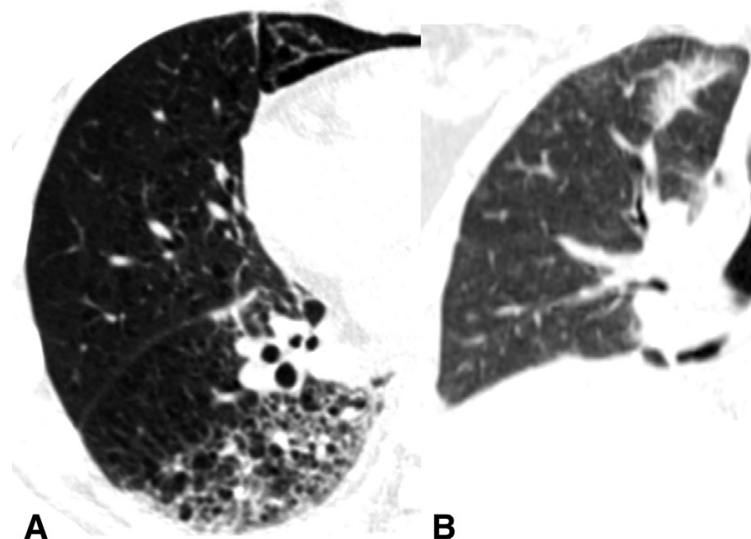

A

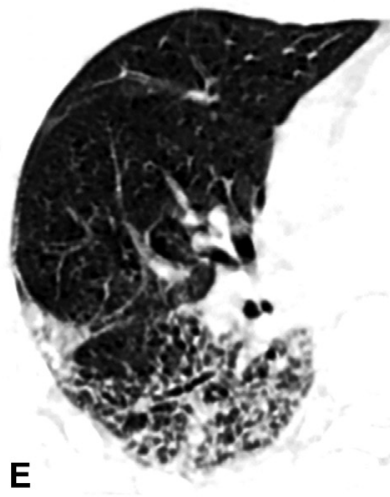

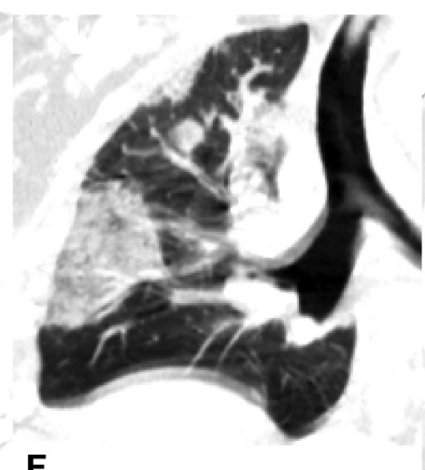

$\mathbf{F}$

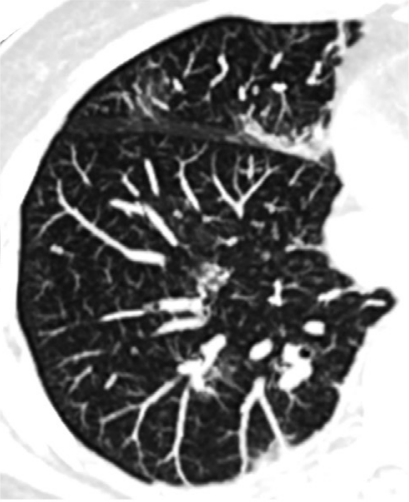

C

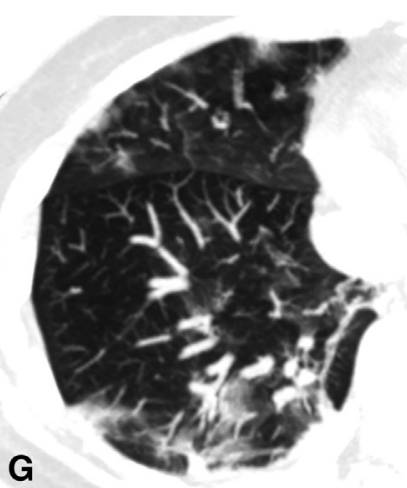

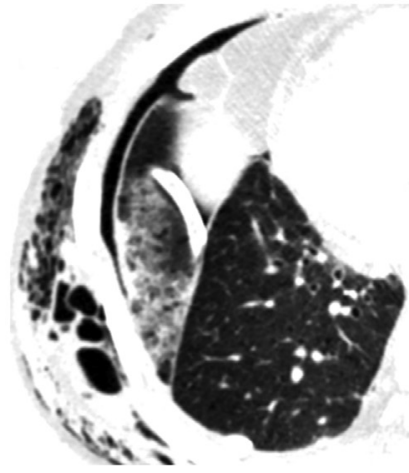

D

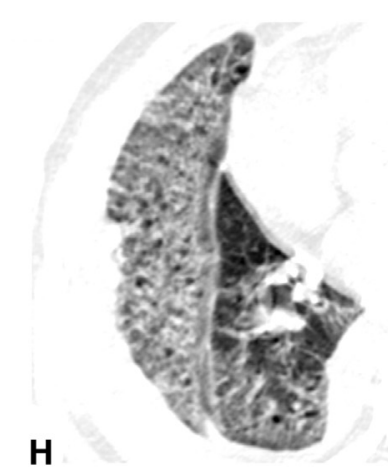

FIGURE 3. CT findings of COVID-19, overshadowed by postoperative changes at the onset, shows progression on repeated CT of the chest and typical signs of progressive viral pneumonia. A, A 61-year-old male patient (case ID 5) 6 days after left lower lobectomy. He had intermittent fever for 3 days with CT findings of emphysema, reticular areas of increased opacity, and irregular patchy consolidation. His repeat CT scan after 5 days shows increased extent and intensity of lesions, suspicious for viral pneumonia (E). B, Chest CT of a 56-year-old female patient (case ID 3) 11 days after left lower lobectomy shows irregular subsolid patchy opacity in left upper lobe. After 5 days (F), the lesion has increased in size and number, with consolidation, pleural effusion and interlobular septal thickening. C, CT of the chest of a 66-year-old female patient (case ID 10) 10 days after left lung wedge resection of upper lobe with basal segmentectomy. CT scan shows small irregular GGO in the right upper lobe and subpleural cord-like consolidation (C), which were not rare as postoperative reactive change. After 8 days, CT shows typical signs of viral pneumonia $(\mathrm{G})$ : diffuse ground glass opacifications with "paving stone" signs and, irregular subpleural cord-like consolidation. D, A 68-year-old male patient (case ID 2) 12 days after right lower lobectomy. Chest CT (D) shows pneumothorax, subcutaneous emphysema, postoperative changes, and inflammation around chest drain. After 18 days, he had sudden onset of fever and CT scan revealed (H) multiple diffuse GGOs in the lung peripheries with reticular consolidation.

artery atherosclerosis (coronary artery disease reporting and data system 1). Of the 3 fatal cases, matched analysis over a much larger sample size is required to answer whether surgery or types of surgery increase morbidity and mortality in patients with COVID-19.

We observed leukocytosis with lymphopenia in 10 cases and leukopenia in 2 cases $(18.2 \%)$, which differs from previously reported COVID-19 cases with an incidence of $5.9 \%, 33.7 \%$, and $70 \%$, respectively. ${ }^{9}$ Leukocytosis after major surgeries is physiological in the early postoperative period, and in other postoperative settings, lymphopenia can occur in $22 \%$ to $35.6 \%$ patients within 7 days. ${ }^{10,11}$ Thoracic surgery is also associated with lymphocyte reduction. ${ }^{12}$ These nonspecific postoperative laboratory changes make detection of infection on these parameters alone extremely challenging. Nonetheless, persisting abnormal white cell counts for more than 1 week is infrequent postoperatively but is common in this case series of COVID-19. In addition, we observed an impressive reduction of lymphocyte and eosinophil counts in all cases, suggesting their prognostic value should be explored in future studies with larger sample sizes. In this case series, the average time from symptom onset to rt-PCR-confirmed diagnosis was about 2 weeks, a time frame unsuitable for hospital practice, which is highly dependent on rapid diagnosis and isolation of cases in hospitalized patients for infection control. Serum antibody detection has better reported sensitivity $(88.66 \%)$ and specificity $(90.63 \%)^{13}$; however, the time to their detection remains uncertain. We know that immunoglobulin $\mathrm{M}$ became detectable 3 to 6 days after severe acute respiratory syndrome infection, ${ }^{14}$ and if this is similar in the case of COVID-19 such delays will remain challenging in the hospital setting. 
TABLE 2. Clinical characteristics of 11 patients related to COVID-19

\begin{tabular}{|c|c|}
\hline Characteristics related to COVID-19 & n $(\%)$ \\
\hline History of exposure to Huanan market & $0(0.0)$ \\
\hline Positive postoperative exposure history & $10(90.9)$ \\
\hline $\begin{array}{l}\text { Symptom of onset } \\
\text { Dry cough } \\
\text { Dyspnea } \\
\text { Fever }\end{array}$ & $\begin{array}{l}1(9.1) \\
2(18.2) \\
8(72.7)\end{array}$ \\
\hline $\begin{array}{l}\text { Sign and symptom after onset } \\
\text { Fever } \\
\quad \text { Maximum temperature, }{ }^{\circ} \mathrm{C}\end{array}$ & $11(100.0)$ \\
\hline $\begin{array}{l}38-39 \\
\geq 39\end{array}$ & $\begin{array}{l}6(54.5) \\
5(45.5)\end{array}$ \\
\hline Dyspnea & $11(100.0)$ \\
\hline Chest tightness & $10(90.9)$ \\
\hline Fatigue & $10(90.9)$ \\
\hline Dry cough & $9(81.8)$ \\
\hline Loss of appetite & $6(54.5)$ \\
\hline Nausea & $6(54.5)$ \\
\hline Headache & $6(54.5)$ \\
\hline Cough with sputum & $4(36.4)$ \\
\hline Diarrhea & $3(27.3)$ \\
\hline Dizziness & $2(18.2)$ \\
\hline Rhinorrhea & $1(9.1)$ \\
\hline Pleural effusion & $6(54.5)$ \\
\hline \multicolumn{2}{|l|}{ Laboratory results } \\
\hline \multicolumn{2}{|l|}{ Leucocytes (reference $3.5-9.5 \times 10^{9}$ per L) } \\
\hline Leukocytosis & $11(100.0)$ \\
\hline Leukopenia (sequential to leukocytosis) & $2(18.2)$ \\
\hline \multicolumn{2}{|l|}{ Lymphocyte count (reference $1.1-3.2 \times 10^{9}$ per L) } \\
\hline Lymphopenia & $10(90.9)$ \\
\hline \multicolumn{2}{|l|}{ Eosinophil count (reference $0.02-0.52 \times 10^{9}$ per L) } \\
\hline Eosinopenia & $11(100.0)$ \\
\hline Persist eosinopenia during disease course & $9(81.8)$ \\
\hline Elevated ALT (reference $\leq 41 \mathrm{U} / \mathrm{L}$ ) & $8(72.7)$ \\
\hline Elevated AST (reference $\leq 40 \mathrm{U} / \mathrm{L}$ ) & 7 (63.6) \\
\hline Elevated creatinine (reference $59-104 \mu \mathrm{mol} / \mathrm{L}$ ) & $0(0.0)$ \\
\hline Elevated LDH (reference 135-225 U/L) & $11(100.0)$ \\
\hline \multicolumn{2}{|l|}{ Clinical outcome } \\
\hline Recovery & $8(72.7)$ \\
\hline Death & $3(27.3)$ \\
\hline \multicolumn{2}{|l|}{ Clinical pattern of COVID-19 } \\
\hline Nonsevere & $4(36.4)$ \\
\hline Severe & $4(36.4)$ \\
\hline Critical & $3(27.3)$ \\
\hline
\end{tabular}

Detailed information for each patient is listed in supplementary table. COVID-19, Coronavirus disease 2019; $A L T$, alanine aminotransferase; $A S T$, aspartate aminotransferase; $L D H$, lactate dehydrogenase.

Postoperative changes from thoracic surgery may overshadow early CT signs of COVID-19 infection. Through retrospective analysis, we found 5 cases of misinterpreted $\mathrm{CT}$ of the chest (1 preoperatively, and 4 postoperatively), which had rapid progression of GGOs on repeated CT scans indicative of active COVID-19 infection. One had ill-defined peripheral GGO with interstitial pneumonia before operation (Figure 2). The remaining 4 had irregular patchy or cord-like consolidation, small irregular GGO and reticular areas of increased opacity and were misinterpreted as postoperative reactive changes, which later on turned became clearly consistent with active viral pneumonia (Figure 3). Hence, a CT scan at a single time point cannot exclude suspicious Sars-CoV-2 infection; rather, repeated CT scans during the postoperative course can assist in diagnosis. During the outbreak, we had to continue emergent surgeries under the risk of COVID-19. As a result of our experience we increased our precautions, replacing postoperative chest radiographs with $\mathrm{CT}$ scans and ordering COVID-19 rt-PCR and serum antibody tests for patients with fever, cough, dyspnea, lymphopenia, eosinopenia, or atypical signs of inflammation on chest CT.

Although a limited sample size, our experience suggests that physicians should be aware of a possible greater risk of death in patients with COVID-19 who have $\geq 5$ lung segments resected and persistent severe hypoproteinemia, hypoalbuminemia, and elevated liver enzymes after thoracic surgeries.

In general, patients infected with COVID-19 who underwent recent thoracic surgery were found to have greaterthan-anticipated incidence of severe illness $(36.4 \%)$ and fatality rate $(27.3 \%)$. As a result of this, nonemergent surgeries were postponed locally, including stage I thoracic malignancies (except for small cell cancer and low differentiation cancer). Case detection in the incubation period remains challenging both pre- and postoperatively. Similarities between the usual thoracic postoperative course and symptoms of COVID-19 viral pneumonia may cause delays in diagnosis. In our experience, if operating in this pandemic environment for any cause, all patients should undergo the following management regimen: a preadmission CT of the chest, oropharyngeal swab, and serum antibody test for COVID-19; if negative, quarantine in a hospital ward for 1 week should be implemented; a second oropharyngeal swab and serum antibody test for COVID-19 should then be performed; if both tests are negative, the patient can undergo the planned operation. Contact restriction is required for hospitalized patients.

Postoperative patients with symptoms or known history of exposure to COVID-19 should be quarantined and monitored dynamically for symptoms and laboratory abnormalities by repeat CTs of the chest postoperatively.

\section{Limitations}

There are some methodologic limitations to this case series. Due to the retrospective nature of this analysis, the presumed date of exposure and symptom onset from medical records and personal statements may be affected by recall bias. The baseline characteristic of the patient varied with respect to underlying comorbidities and preoperative pulmonary lung function; additionally, the different types of 
TABLE 3. Potential risk factors for critical COVID-19 after thoracic surgery (Fisher exact test and $t$ test)

\begin{tabular}{|c|c|c|c|}
\hline Binary variables & Survival $(\mathbf{n}=\mathbf{8})$ & Death $(n=3)$ & $P$ value \\
\hline Sex & & & 1.000 \\
\hline Female & $2(25.0 \%)$ & $1(33.3 \%)$ & \\
\hline Male & $2(75.0 \%)$ & $6(66.7 \%)$ & \\
\hline \multicolumn{4}{|l|}{ Age, y } \\
\hline $50-59$ & $4(50.0 \%)$ & $1(33.3 \%)$ & 1.000 \\
\hline $60-69$ & $4(50.0 \%)$ & $2(66.7 \%)$ & \\
\hline \multicolumn{4}{|l|}{ Arterial hypertension } \\
\hline No & $7(87.5 \%)$ & $1(33.3 \%)$ & .152 \\
\hline Yes & $1(12.5 \%)$ & $2(66.7 \%)$ & \\
\hline \multicolumn{4}{|l|}{ Pattern of fever } \\
\hline Remittent fever & $0(0.0 \%)$ & $3(100 \%)$ & .006 \\
\hline Intermittent fever & $8(100 \%)$ & $0(0.0 \%)$ & \\
\hline \multicolumn{4}{|l|}{ Resected lung segments } \\
\hline$\geq 5$ & $1(12.5 \%)$ & $3(100 \%)$ & .024 \\
\hline$<5$ & $7(87.5 \%)$ & $0(0.0 \%)$ & \\
\hline \multicolumn{4}{|l|}{ Elevated AST or ALT } \\
\hline No & $0(0.0 \%)$ & $2(66.7 \%)$ & .055 \\
\hline Yes & $8(100 \%)$ & $1(33.3 \%)$ & \\
\hline Continuous variables & Mean \pm SD $(n=8)$ & Mean $\pm \operatorname{SD}(n=3)$ & \\
\hline Reduction in total protein, $\mathrm{g} / \mathrm{L}$ & $8.13 \pm 4.45$ & $15.60 \pm 5.67$ & .045 \\
\hline Reduction in albumin, $g / L$ & $5.56 \pm 3.31$ & $14.63 \pm 3.00$ & .003 \\
\hline Peak LDH value, U/L & $340.13 \pm 119.98$ & $543.33 \pm 170.72$ & .050 \\
\hline Nadir of lymphocyte count, $\times 10^{9} / \mathrm{L}$ & $0.52 \pm 0.39$ & $0.2500 \pm 0.061$ & .285 \\
\hline
\end{tabular}

Detailed information for each patient is listed in supplementary table. $A S T$, Aspartate aminotransferase; $A L T$, alanine aminotransferase; $S D$, standard deviation; $L D H$, lactate dehydrogenase.

surgery completed may have variable impacts on clinical course and outcomes. With the small sample size, we can neither identify causality of factors associated with death nor control for confounders and effect modifiers. All enrolled patients acquired COVID-19 infection in Wuhan in the early period of outbreak and they were operated on in a high-volume surgical center with relatively highresource setting, so generalizability may be limited to similar settings as opposed to all operating settings.

\section{Conflict of Interest Statement}

Authors have nothing to disclose with regard to commercial support.

\section{References}

1. Bai Y, Yao L, Wei T, Tian F, Jin D-Y, Chen L, et al. Presumed asymptomatic carrier transmission of COVID-19. JAMA. 2020;323:1406-7.

2. Xu Z, Li S, Tian S, Li H, Kong L-Q. Full spectrum of COVID-19 severity still being depicted. Lancet. 2020;395:947-8.

3. Young BE, Ong SWX, Kalimuddin S, Low JG, Tan SY, Loh J, et al. Epidemiologic features and clinical course of patients infected with SARS-CoV-2 in Singapore. JAMA. 2020;323:1488-94.

4. Wu Z, McGoogan JM. Characteristics of and important lessons from the coronavirus disease 2019 (COVID-19) outbreak in China: summary of a report of 72314 cases from the Chinese center for disease control and prevention. JAMA. 2020; 323:1239-42.

5. Chinese National Health Commission. Chinese Clinical Guidance for COVID19 Pneumonia Diagnosis and Treatment (7th edition), 2020. Available at: http:// www.nhc.gov.cn/yzygj/s7653p/202003/46c9294a7dfe4cef80dc7f5912eb1989.sh tml. Accessed March 27, 2020.

6. Chen T, Wu D, Chen H, Yan W, Yang D, Chen G, et al. Clinical characteristics of 113 deceased patients with coronavirus disease 2019: retrospective study. BMJ. 2020;368:m1091.

7. Ai T, Yang Z, Hou H, Zhan C, Chen C, Lv W, et al. Correlation of chest CT and RT-PCR testing in coronavirus disease 2019 (COVID-19) in China: a report of 1014 cases. Radiology. 2020;26:200642.

8. Crompton JG, Crompton PD, Matzinger P. Does atelectasis cause fever after surgery? Putting a damper on dogma. JAMA Surg. 2019;154:375-6.

9. Huang C, Wang Y, Li X, Ren L, Zhao J, Hu Y, et al. Clinical features of patients infected with 2019 novel coronavirus in Wuhan, China. Lancet. 2020;395: 497-506.

10. Iwata E, Shigematsu H, Okuda A, Morimoto Y, Masuda K, Nakajima H, et al. Lymphopenia at 4 days postoperatively is the most significant laboratory marker for early detection of surgical site infection following posterior lumbar instrumentation surgery. Asian Spine J. 2016;10:1042-6.

11. Jones SM, McCracken C, Alsoufi B, Mahle WT, Oster ME. Association of preoperative cell counts with outcomes after operation for congenital heart disease. Ann Thorac Surg. 2018;106:1234-40.

12. Lugg S, Agostini P, Kerr A, Kalkat M, Rajesh P, Steyn R, et al. The role of lymphopenia in the development and severity of postoperative pulmonary complications after lung surgery. Eur Respir J. 2017;50(suppl 61):OA3224.

13. Li Z, Yi Y, Luo X, Xiong N, Liu Y, Li S, et al. Development and clinical application of a rapid IgM-IgG combined antibody test for SARS-CoV-2 infection diagnosis. J Med Virol. 2020;1-7.

14. Lee HK, Lee BH, Seok SH, Baek NW, Lee HY, Kim DJ, et al. Production of specific antibodies against SARS-coronavirus nucleocapsid protein without cross reactivity with human coronaviruses 229E and OC43. J Vet Sci. 2010;11:165-7.

Key Words: COVID-19, surgery, lung cancer, esophageal cancer, postoperative, Sars-Cov-2 
TABLE E1. Clinical characteristics and treatment of 11 postoperative patients infected with COVID-19

\begin{tabular}{|c|c|c|c|c|c|c|c|c|c|c|c|}
\hline Case ID. & 1 & 2 & 3 & 4 & 5 & 6 & 7 & 8 & 9 & 10 & 11 \\
\hline Severity of COVID-19 & Critical & Critical & Critical & Severe & Severe & Severe & Severe & Mild & Mild & Mild & Mild \\
\hline Date of surgery & $2020 / 1 / 17$ & $2020 / 1 / 2$ & $2020 / 1 / 22$ & $2020 / 1 / 16$ & $2020 / 1 / 20$ & $2020 / 1 / 16$ & $2020 / 1 / 19$ & $2020 / 1 / 16$ & $2020 / 1 / 9$ & $2020 / 1 / 20$ & 2020/1/13 \\
\hline Positive exposure & NA & Yes & Yes & Yes & Yes & Yes & Yes & Yes & Yes & Yes & Yes \\
\hline Date of post-op exposure & NA & $2020 / 1 / 23$ & $2020 / 1 / 23$ & $2020 / 1 / 17$ & $2020 / 1 / 20$ & $2020 / 1 / 17$ & $2020 / 1 / 19$ & $2020 / 1 / 17$ & $2020 / 1 / 20$ & $2020 / 1 / 20$ & 2020/1/25 \\
\hline date of COVID-19 test + & $2020 / 1 / 21$ & $2020 / 2 / 11$ & $2020 / 2 / 12$ & $2020 / 2 / 10$ & $2020 / 2 / 3$ & $2020 / 2 / 1$ & $2020 / 2 / 3$ & $2020 / 2 / 2$ & $2020 / 2 / 8$ & $2020 / 2 / 3$ & $2020 / 2 / 22$ \\
\hline Outcome & Death & Death & Death & Recovery & Recovery & Recovery & Recovery & Recovery & Recovery & Recovery & Recovery \\
\hline Date of death/discharge & $2020 / 1 / 22$ & $2020 / 2 / 13$ & $2020 / 2 / 26$ & $2020 / 3 / 27$ & $2020 / 3 / 6$ & $2020 / 2 / 23$ & $2020 / 3 / 21$ & $2020 / 3 / 5$ & $2020 / 2 / 29$ & $2020 / 2 / 29$ & $92020 / 3 / 25$ \\
\hline Onset symptoms & Fever & Fever & Fever & Dyspnea & Fever & Fever & Dyspnea & Fever & Dry cough & Fever & Fever \\
\hline Fever peak $\left({ }^{\circ} \mathrm{C}\right)$ & 39.5 & 38.7 & 39.6 & 39.0 & 39.4 & 39.3 & 38.4 & 38.6 & 38.0 & 38.4 & 38.4 \\
\hline Normothermia for $3 \mathrm{~d}$ & No & No & No & Yes & Yes & Yes & Yes & Yes & Yes & Yes & Yes \\
\hline Dyspnea & Yes & Yes & Yes & Yes & Yes & Yes & Yes & Yes & Yes & Yes & Yes \\
\hline Chest tightness & Yes & Yes & Yes & Yes & Yes & Yes & Yes & Yes & Yes & No & Yes \\
\hline Fatigue & Yes & Yes & Yes & Yes & Yes & Yes & Yes & No & Yes & Yes & Yes \\
\hline Dry cough & Yes & Yes & Yes & Yes & Yes & Yes & No & No & Yes & Yes & Yes \\
\hline Loss of appetite & No & Yes & Yes & Yes & No & No & Yes & No & Yes & No & Yes \\
\hline Nausea & Yes & Yes & Yes & No & No & Yes & No & No & Yes & No & Yes \\
\hline Headache & Yes & Yes & Yes & No & No & No & Yes & No & Yes & No & Yes \\
\hline Sputum & Yes & Yes & No & No & Yes & No & Yes & No & No & No & No \\
\hline Diarrhea & Yes & No & Yes & Yes & No & No & No & No & No & No & No \\
\hline Dizziness & Yes & No & No & No & No & No & No & No & Yes & No & No \\
\hline Rhinorrhea & No & Yes & No & No & No & No & No & No & No & No & No \\
\hline Pleural effusion & No & Yes & Yes & No & Yes & No & No & No & Yes & Yes & Yes \\
\hline $\mathrm{SaO}_{2}<93 \%$ & Yes & Yes & Yes & Yes & Yes & Yes & Yes & No & No & No & No \\
\hline Nadir $\mathrm{SaO}_{2}(\%)$ & 85 & 80 & 60 & 92 & 90 & 92 & 92 & 97 & 98 & 94 & 95 \\
\hline Leukocytosis & Yes & Yes & Yes & Yes & Yes & Yes & Yes & Yes & Yes & Yes & Yes \\
\hline Leukopenia & Yes & No & No & No & No & No & No & No & Yes & Yes & No \\
\hline Lymphopenia & Yes & Yes & Yes & Yes & Yes & Yes & Yes & Yes & Yes & Yes & Yes \\
\hline Eosinopenia & Yes & Yes & Yes & Yes & Yes & Yes & Yes & Yes & Yes & Yes & Yes \\
\hline Lowest eosinophils, $\times 10^{9} / \mathrm{L}$ & 0 & 0 & 0 & 0 & 0 & 0 & 0 & 0.01 & 0 & 0 & 0 \\
\hline Elevation of AST or ALT & No & Yes & No & Yes & Yes & Yes & Yes & Yes & Yes & Yes & Yes \\
\hline AST increase & No & Yes & No & Yes & Yes & No & No & Yes & Yes & Yes & Yes \\
\hline ALT increase & No & Yes & No & Yes & Yes & Yes & Yes & Yes & Yes & No & Yes \\
\hline Peak LDH value, U/L & 348 & 664 & 618 & 233 & 354 & 309 & 613 & 263 & 349 & 253 & 347 \\
\hline $\begin{array}{l}\text { Reduction in total } \\
\text { protein, } \mathrm{g} / \mathrm{L}\end{array}$ & 16.1 & 21.0 & 9.7 & 5.2 & 6.2 & 8.2 & 15.4 & 6.0 & 13.7 & 8.3 & 2.0 \\
\hline $\begin{array}{l}\text { Reduction in } \\
\text { albumin, } \mathrm{g} / \mathrm{L}\end{array}$ & 12.0 & 14.0 & 17.9 & 3.5 & 2.2 & 3.5 & 9.9 & 4.7 & 8.0 & 10.2 & 2.4 \\
\hline $\begin{array}{l}\text { Nadir of } \\
\quad \text { lymphocytes, } \times 10^{9} / \mathrm{L}\end{array}$ & 0.18 & 0.29 & 0.28 & 0.28 & 0.39 & 0.25 & 0.68 & 1.20 & 0.23 & 0.65 & 0.28 \\
\hline Oxygen supplementation & Yes & Yes & Yes & Yes & Yes & Yes & Yes & Yes & Yes & Yes & Yes \\
\hline Mechanical ventilation & BPAP & IMV & IMV & No & No & No & No & No & No & No & No \\
\hline Corticosteroid & No & No & Yes & Yes & Yes & Yes & Yes & No & No & No & No \\
\hline Anti-viral therapy & $\mathrm{O}$ & $\mathrm{O}+\mathrm{U}$ & $\mathrm{O}+\mathrm{U}$ & $\mathrm{O}+\mathrm{U}$ & $\mathrm{O}+\mathrm{U}$ & $\mathrm{O}+\mathrm{L}+\mathrm{R}$ & $\mathrm{O}$ & $\mathrm{O}+\mathrm{U}$ & $\mathrm{O}+\mathrm{U}$ & $\mathrm{O}$ & $\mathrm{O}+\mathrm{U}$ \\
\hline IV IgG & No & No & Yes & No & No & No & Yes & No & No & Yes & No \\
\hline
\end{tabular}

COVID-19, Coronavirus disease 2019; $\mathrm{NA}$, not available; Post-op, postoperative; $\mathrm{SaO}_{2}$, oxygen saturation; $A S T$, aspartate aminotransferase; $A L T$, alanine aminotransferase; $L D H$, lactate dehydrogenase; $B P A P$, bilevel positive airway pressure; $I M V$, intermittent mandatory ventilation; $O$, oseltamivir; $U$, umifenovir; $L$, lopinavir; $R$, ritonavir; $\mathrm{O}+U, O+L$, $O+R$, oseltamivir has been replaced by umifenovir, lopinavir, or ritonavir, no one received combined antiviral therapy; $I V I g G$, intravenous immunoglobulin $\mathrm{G}$ 
UI TABLE E2. Baseline characteristics of 11 postoperative patients before the onset of COVID-19

\begin{tabular}{|c|c|c|c|c|c|c|c|c|c|c|c|}
\hline Case ID & 1 & 2 & 3 & 4 & 5 & 6 & 7 & 8 & 9 & 10 & 11 \\
\hline Severity & Critical & Critical & Critical & Severe & Severe & Severe & Severe & Nonsevere & Nonsevere & Nonsevere & Nonsevere \\
\hline Age, y & 63 & 68 & 56 & 62 & 61 & 57 & 57 & 51 & 52 & 66 & 69 \\
\hline Sex & Male & Male & Female & Male & Male & Male & Male & Male & Female & Female & Male \\
\hline Comorbidity & IP & $\begin{array}{l}\text { COPD } \\
\text { Colon } \\
\text { cancer }\end{array}$ & $\begin{array}{l}\text { HTN } \\
\text { CAD }\end{array}$ & No & No & CAD & COPD & HTN & No & $\begin{array}{l}\mathrm{HBV} \\
\mathrm{CAD}\end{array}$ & COPD \\
\hline Cigarette smoking & Current & Formal & No & Current & Current & No & Current & No & No & No & Current \\
\hline Smoking index & 1600 & 1600 & 0 & 400 & 800 & 0 & 600 & 0 & 0 & 0 & 400 \\
\hline FEV1 & 2.49 & 1.39 & 2.77 & - & 2.42 & 3.07 & 2.36 & 3.17 & 2.54 & 2.04 & 3.06 \\
\hline FEV1/FVC $\%$ & 70.1 & 58.52 & 72.51 & - & 83 & 75.11 & 65.09 & 75.25 & 84 & 85 & 64.93 \\
\hline Operation & RLLL & RLLL & RLLL & $\begin{array}{l}\text { McKeown } \\
\text { EE }\end{array}$ & LLLL & $\begin{array}{l}\text { LLLL + } \\
\text { S4S5 sleeve } \\
\text { resection }\end{array}$ & RULL & RLLW & LULL & $\begin{array}{l}\text { LULW + } \\
\text { LLLBSE }\end{array}$ & $\begin{array}{c}\text { McKeown } \\
\text { EE }\end{array}$ \\
\hline Lymphadenectomy & Yes & Yes & No & Yes & Yes & Yes & Yes & No & Yes & Yes & Yes \\
\hline Approach & VATS & Open & VATS & Open & VATS & Open & VATS & VATS & VATS & VATS & Open \\
\hline $\begin{array}{l}\text { Duration of } \\
\text { surgery (min) }\end{array}$ & 200 & 280 & 110 & 410 & 150 & 220 & 165 & 140 & 170 & 130 & 385 \\
\hline $\begin{array}{l}\text { GGO on } \\
\quad \text { preoperative CT }\end{array}$ & Yes & No & No & No & No & No & No & No & No & Yes & No \\
\hline $\begin{array}{l}\text { First CT sign of } \\
\text { COVID-19 }\end{array}$ & Consolidation & $\begin{array}{l}\text { Subsolid } \\
\text { opacity }\end{array}$ & Consolidation & GGO & GGO & GGO & GGO & GGO & GGO & GGO & GGO \\
\hline Post-op complication & No & PAL & No & No & No & No & No & No & $\mathrm{H}+\mathrm{SCA}$ & No & No \\
\hline Pre-op pathology & LSCC & LADC & - & SCC & - & - & - & - & - & - & SCC \\
\hline Post-op pathology & LSCC & LADC & PSP & ESCC & LADC & LADC & LADC & $\mathrm{BE}$ & LADC & LADC & ESCC \\
\hline pTNM & T2aNOMOR0 & $\begin{array}{l}\text { T1N2 } \\
\text { M0R0 }\end{array}$ & NA & $\begin{array}{l}\text { T3N0 } \\
\text { M0R0 }\end{array}$ & $\begin{array}{l}\text { T2N2 } \\
\text { M0R0 }\end{array}$ & $\begin{array}{l}\text { T2N2 } \\
\text { M0R0 }\end{array}$ & $\begin{array}{l}\text { T1bN0 } \\
\text { M0R0 }\end{array}$ & NA & $\begin{array}{l}\text { T1bN0 } \\
\text { M0R0 }\end{array}$ & $\begin{array}{l}\text { T1aNOR0 } \\
\text { T1bNOR0 }\end{array}$ & $\begin{array}{l}\text { T1bN0 } \\
\text { M0R0 }\end{array}$ \\
\hline Stage & IA & IIIA & NA & IIB & IIIA & IIIA & IA & NA & IA & IA, IB & IB \\
\hline
\end{tabular}

$I P$, Interstitial pneumonia; $C O P D$, chronic obstructive pulmonary disease; $H T N$, hypertension; $C A D$, atherosclerosis of coronary artery; $H B V$, hepatitis B virus; $F E V I$, forced expiratory volume in 1 second; $F V C$, forced vital capacity; $R L L L$, right lower lobe lobectomy; $M c K e w o n E E$, McKewon esophagectomy with gastric tube interposition; $L L L L$, left lower lobe lobectomy; $R U L L$, right upper lobe lobectomy; $R L L W$, right lower lobe wedge resection; $L U L L$, left upper lobe lobectomy; LLLBSE, left lower lobe basal segmentectomy; VATS, video-assisted thoracic surgery; GGO, ground-glass opacity; CT, computed tomography; COVID-19, coronavirus disease 2019; Post-op, postoperative; $P A L$, prolonged air leak; $H+S C A$, hypokalemia/sudden cardiac arrest; Pre-op, preoperative; $L S C C$, lung squamous cell cancer; $L A D C$, lung adenocarcinoma; $S C C$, squamous cell carcinoma; $P S P$, pulmonary sclerosing pneumocytoma; $E S C C$, esophageal squamous cell cancer; $B E$, bronchiectasis; $N A$, not available. 